\title{
Numerical Analysis by Computational Fluid Dynamic Simulation of Fluid Flow in A T- Junction
}

\author{
Marwa S. Luaibi ${ }^{1}$, Mohammed A. Abdulwahid ${ }^{2}$ \\ \{Marwa.salman1988@gmail.com¹/Marwa.salman@stu.edu.iq ${ }^{1}$, mohw2016@stu.edu.iq² \\ Engineering Technical College, Southern Technical University, Iraq ${ }^{1{ }^{2}}$
}

\begin{abstract}
The flow in a T-junction is very important in industrial and equipment. Prediction of the loss coefficient and velocity profile of fluid with the turbulent incompressible flow in T-junction pipe for non-symmetrical dividing and non-symmetrical combining helps to understand this type of fitting. The angle of the tee is $90^{\circ}$, sharp edge, the area ratio is equal to one and Three-dimensional the specification of geometry at steady state. The model of turbulent uses the stander k- $\varepsilon$ and solving the Navies- Stocks equation by finite volume method in the SIMPLE algorithm in ANSYS FLUENT R1 2020. Comparison of the numerical results with previous work to study the effect of the flow rate ratio with different Reynolds numbers in the range (3000-30000). The results show the loss coefficient is independent of Re numbers. The non-symmetrical dividing the maximum flow move in the straight pipe when the change flow rate ratio to $(0.8)$ forced the fluid to move in the branch and formation high vortex and recirculation. The nonsymmetrical combining the high velocity in outlet branch with small eddies especially increased at a flow rate ratio (0.8).
\end{abstract}

Keywords: T-junction, non-symmetrical, turbulent flow, loss coefficient, flow rate ratio.

\section{Introduction}

The networks and industrial contain several pipes and $\mathrm{T}$-junction. The $\mathrm{T}$ - junction consider is the most common complex section of networks pipe that is mainly employed for the transportation and supply of gases and liquids. The T-junction is utilization to merge (combining) flows from branch pipes to the main pipe. Separate (dividing) the flow from the main pipe to several branching pipes. as shown in Fig 1.

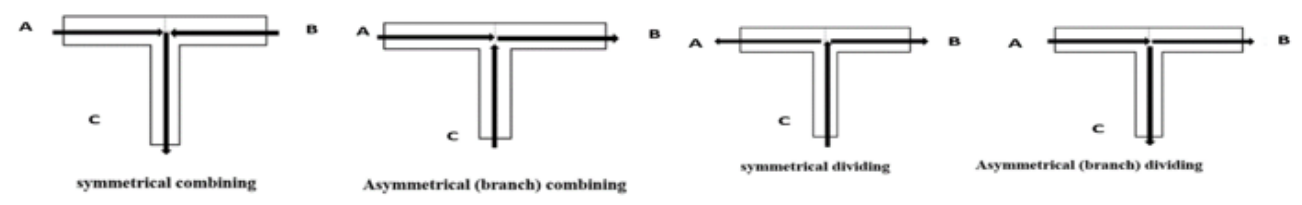

Fig 1. Various possibilities of fluid in the junction. 
The numerical simulations can provide a lot of insight into this area and given the scientific, academic, and industrial relevance of the understanding of this type of flow. The loss coefficient and energy losses at junctions have been studied for several years. Therefore a more developing description of the T-junction had to be arrived at by Miller [1] cases that the cause of pressure loss coefficient and major energy loss and pressure for $\mathrm{T}$ and $\mathrm{Y}$ junctions is due to the converge and diverge of flows with different areas ratios, flow rate ratio, and angle. In A. Marc Serre et al [2] Although a considerable quantity of theoretical research exists on pressure loss coefficients for tee and pressure drop (head losses). Sierra Espinosa et al. [3] scrutinized roundedge tees and compared a limited set of measurements with simulations by the standard Reynolds stress (RSM) turbulence model, standard k- $\varepsilon$ model, and (RNG) k- $\varepsilon$ models. These models were able to predict the mean flow for numerical Fluent and comparison with experimental. G. Gan et al. [4] the pressure loss coefficient determines the use of fluent CFD for division and combination for duct junction with a square cross-section. Another author's prompt description of the T- junction is provided by Oka [5] to determine the pressure loss coefficient and power losses coefficient for combining and dividing, and comparison with the experimental result for area ratio 11.44. N. Crawford [6] the total coefficients, total pressure, equivalent length evaluated by the experiment and the CFD ANSYS FLUENT computation for air working fluid for T, Y junction, and elbow. Pérez [7] predicted the loss coefficient has been related to the extrapolated Mach number with different flow rate ratios for symmetrical combining and symmetrical dividing by experimental and numerical in FLUENT. N. P. Costa [8] The flow arrangement is that of a combining flow in a $90^{\circ} \mathrm{T}$-junction with sharp and around corners by numerical and experimental methods, explained the optimize of fluid flow in $\mathrm{T}$ Junction. P. R. Vasava [9] did fundamental work in the field of major head loss and minor losses effort during fluid flow through a T-junction and angles of T-junctions. He calculated the values obtained by simulations in ANSYS FLUENT and compared them with the classical formulas of Vazsonyi and Gardel. Researchers [10-13] Studied the 3D T-Junction for steady-state and turbulent flow by the numerical method in ANSYS and predicted the loss coefficient, pressure drop, and velocity profile in T-junction. Other researchers [14 and 15] Worked by numerical in ANSYS FLUENT and experimental (PIV) measurements to compare velocity profiles and streamline between them. M. D. Bassett et al. [10] developed simple expressions are provided that allow all of the pressure loss coefficients for a three pipe T-junction, with any side branch angle or area ratio, to be calculated. N. A. Ferede [11] Studied The head losses, pressure loss, velocity profile, and drag coefficient in T-junction where the working fluid used the mercury in CFX. The goal of this paper is to calculate the pressure loss coefficient with different flow rate ratios, area ratios equal to one. present the numerical results of turbulent flow. The flow is steady state, the cases of T-junction for non-symmetrical combining and non-symmetrical dividing. The Reynolds number in the range from 3000 to 30000 falls within a range in the real application. The result was extracted from ANSYS FLUENT R1 2020. It is expected thus that the results of this investigation may be of help to engineers dealing with similar Reynolds numbers and flow configurations. chooses the flow rate ratio from (0.1-0.8) to show the effect of the different flow rates on the loss coefficient and velocity profile.

\section{Numerical Description}

\subsection{Geometry}




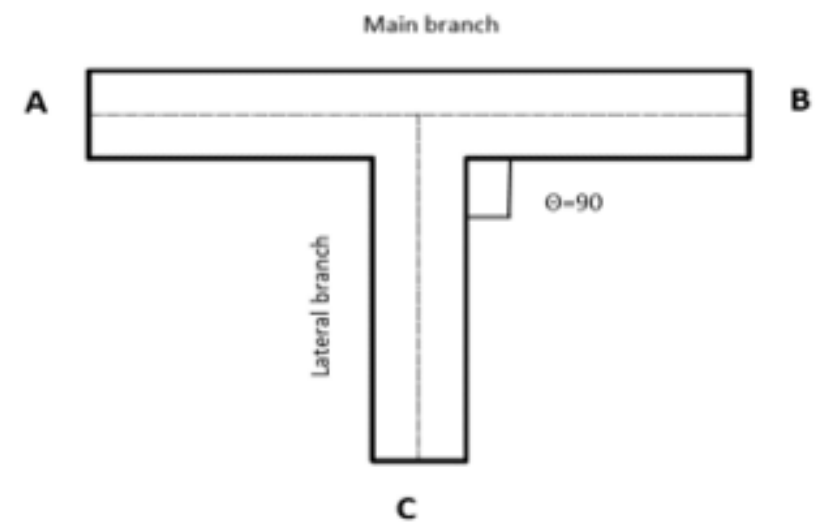

Fig 2. Schematic representation of the T-junction.

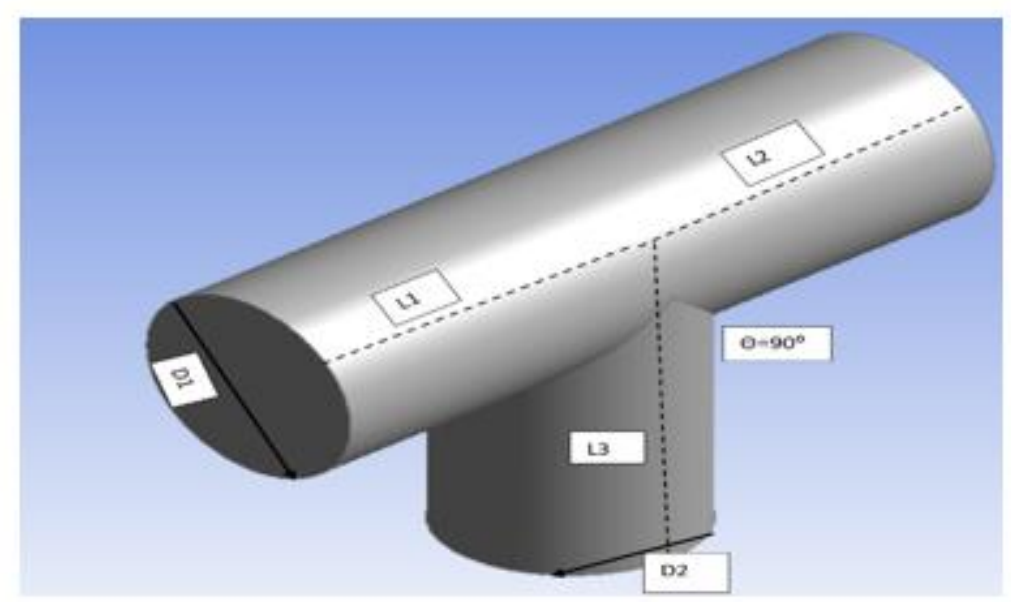

Fig 3. 3D Geometry of T- junction.

The geometry of the fluid domain of the T-junction is created on ANSYS R1 2020 FLUENT to study the fluid flow phenomenon occurring on the fluid in two cases: case1, the fluid flow enters a $\mathrm{T}$ junction from branch $\mathrm{A}$ and outlet from branch $\mathrm{C}$ and $\mathrm{B}$ (non-symmetrical dividing). In case 2, the fluid flow enters from the $A$ and $C$ branches and outlet from $B$ (non-symmetrical combining) as shown in Fig 2. The inner diameters D1of the main inlet branch pipe is $0.0254 \mathrm{~m}$, also the same value as the inner diameter D2 of the lateral branch pipe. the length of each branch, $\mathrm{L}_{1}=\mathrm{L}_{2}=\mathrm{L}_{3}=0.04 \mathrm{~m}$. The flow arrangement is that of combining and dividing flow in a $90^{\circ} \mathrm{T}$-junction with sharp corners. as shown in Fig 3 .

\subsection{CFD Mesh Model}


To establish the CFD mesh model, the flow zone is divided into several subdomains for meshing. The tetrahedron elements are finer and the number of elements is determined by checking computations. The number of elements is (488747) and the number of nodes is (121790) for non-symmetrical dividing and non-symmetrical combining. The element size is $(1 \mathrm{~mm})$ with five boundary layers. Calculations are carried out with commercial finite volume code ANSYS R1 2020 Fluent as shown in Fig 4. To checking the mesh by using mesh independence as shown in Fig 5. Reynold's number is calculated at the same place in T-junction for three planes at velocity $0.04 \mathrm{~m} / \mathrm{s}$ without changing another parameter just element size. Choose this meshing to save time and good accuracy.

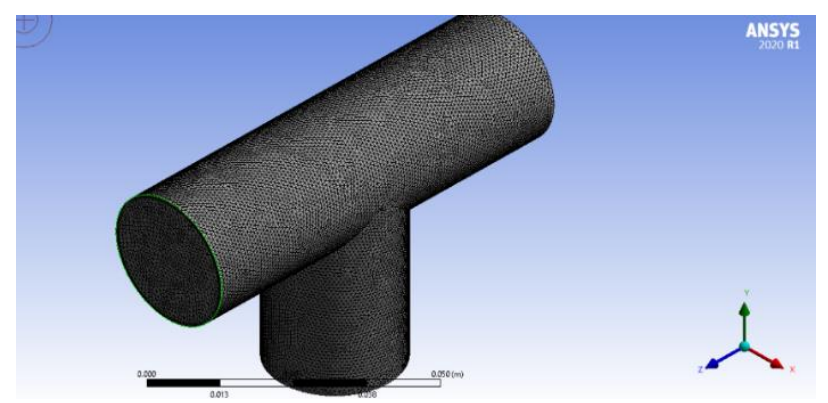

Fig 4. the T-junction meshing.

\begin{tabular}{|c|r|r|r|c|c|c|}
\hline $\begin{array}{c}\text { element } \\
\text { size }\end{array}$ & node & element & skwence & Re1 & Re2 & Re3 \\
\hline $\mathbf{6 m m}$ & 2010 & 4393 & 0.8639 & 851.8836 & 977.0119 & 183.1929 \\
\hline $\mathbf{3 m m}$ & 8384 & 22922 & 0.8804 & 830.9025 & 959.8225 & 156.2713 \\
\hline $\mathbf{2} \mathbf{~ m m}$ & 21788 & 69312 & 0.84866 & 843.2889 & 951.9862 & 135.7705 \\
\hline $\mathbf{1 . 5} \mathbf{~ m m}$ & 43643 & 154055 & 0.78561 & 845.8168 & 949.4584 & 135.1133 \\
\hline $\mathbf{1 . 3 m m}$ & 62470 & 231223 & 0.77186 & 851.8836 & 945.9194 & 136.3267 \\
\hline $\mathbf{1 . 2}$ & 76470 & 289938 & 0.78136 & 866.2923 & 952.239 & 135.6694 \\
\hline $\mathbf{1 . 1} \mathbf{m m}$ & 95681 & 373059 & 0.75457 & 868.8201 & 957.5475 & 138.9556 \\
\hline $\mathbf{1 m m}$ & 121790 & 488747 & 0.7971 & 856.1809 & 953.7557 & 136.3772 \\
\hline $\mathbf{0 . 8 m m}$ & 218718 & 932770 & 0.82834 & 866.7979 & 963.8671 & 136.3772 \\
\hline $\mathbf{0 . 7 m m}$ & 309021 & 1368403 & 0.83272 & 872.8647 & 959.8225 & 135.6189 \\
\hline
\end{tabular}

Fig 5. Mesh independent.

\subsection{Boundary Condition and Simulation Parameters}

The water is employed in the simulations with a constant density of $998.2 \mathrm{~kg} / \mathrm{m}^{3}$ and dynamic viscosity of $0.001003 \mathrm{~kg} / \mathrm{ms}$. The fluid is supposed an incompressible flow and constant temperature at $20^{\circ} \mathrm{C}$. It is assumed that no slip boundary condition at all the walls. The boundary condition is velocity inlet (upstream), the velocity is uniform, and the boundary condition at the outlet is pressure outlet (downstream) zero-gauge pressure. The second-order upwind scheme is used for the discretization of transport equations for momentum, $\mathrm{k}$, and $\varepsilon$. The pressure values at the faces were interpolated using the standard scheme and the transport equations are solved using the SIMPLE algorithm. 


\subsection{Governing Equations}

The Naiver-Stokes equations are solved for an incompressible flow, the conservation of mass Equation (1), and momentum Equation (2).

$\frac{\partial u_{i}}{\partial x i}=0$

$\frac{\partial \rho u_{i}}{\partial t}+\frac{\partial \rho u_{j} u_{i}}{\partial x_{j}}=-\frac{\partial \bar{P}}{\partial x_{i}}+\frac{\partial}{\partial x_{j}}\left[\mu\left(\frac{\partial u_{i}}{\partial x_{j}}+\frac{\partial u_{j}}{\partial x_{i}}\right)-\rho \overline{u_{\imath} u_{j}}\right]$

Many researchers have an effort to solve these equations. Naiver-Stokes equations can be solved numerically by using the finite volume method equation (1-2), but the solutions are obtained after making some assumptions and some of them are not stable at high Reynolds number. The k- $\varepsilon$ model is one of the most used turbulence models. It includes two transport equations to represent the turbulent properties of the flow. The first transported variable is turbulent kinetic energy $\mathrm{k}$, and the second transported variable is the turbulent dissipation $\varepsilon$. These variables determine the scale of the turbulence and the energy in the turbulence. $\rho \overline{u_{l} u_{\jmath}}$ represent the last term of equation (2) as a time average eddy shear stress in the momentum equation, where the molecular diffusion shear stress $\mu \frac{\partial \bar{u}}{\partial x_{i}}$. The Transport equations of $\mathrm{k}-\varepsilon$ model for $\mathrm{k}$.

$\frac{\partial}{\partial t}(\rho k)+\frac{\partial}{\partial x_{i}}\left(\rho k u_{i}\right)=\frac{\partial}{\partial x_{j}}\left[\left(\mu+\frac{\mu_{t}}{\sigma_{k}}\right) \frac{\partial k}{\partial x_{i}}\right]+p_{k}-p_{b}-\rho \varepsilon-Y_{k}+S_{k}$

And for $\varepsilon$

$\frac{\partial}{\partial t}(\rho \varepsilon)+\frac{\partial}{\partial x_{i}}\left(\rho \varepsilon u_{i}\right)=\frac{\partial}{\partial x_{j}}\left[\left(\mu+\frac{\mu_{t}}{\sigma_{\varepsilon}}\right) \frac{\partial \varepsilon}{\partial x_{i}}\right]+C_{1 \varepsilon} \frac{\varepsilon}{K}\left(p_{k}+C_{3 \varepsilon} p_{b}\right)-C_{2 \varepsilon} \rho \frac{\varepsilon^{2}}{k}+S_{\varepsilon}$

The turbulent viscosity is modelled as:

$\mu_{t}=\rho C_{\mu} \frac{K^{2}}{\varepsilon}$

Production of $\mathrm{k}$

$P_{k}=-\rho{\overline{U_{l} \dot{U}_{J}}}_{\partial U_{j}}^{\partial x_{i}}$ 
$P_{k}=\mu_{t} S^{2}$

$\mathrm{S}$ is the modulus of the mean rate-of-strain tensor

$S=\sqrt{2 S_{i j} S i j}$

$\mathrm{k}-\varepsilon$ model is only useful in regions with turbulent, high Reynolds number flows. The k- $\varepsilon$ model is most used to describe the behavior of the turbulent flow equation from(3-8). The equations contain five adjustable constants in Table1. The standard $\mathrm{k}-\varepsilon$ model uses values for the constants that are arrived at by comprehensive data fitting for a wide range of turbulent flows:

Table 1. Numerical values of some parameters.

\begin{tabular}{|c|c|c|c|c|}
\hline \multicolumn{1}{|c|}{$\sigma_{\mathrm{k}}$} & $\sigma_{\varepsilon}$ & \multicolumn{2}{c|}{$C_{1 \varepsilon}$} & \multicolumn{2}{c|}{$C 2_{\varepsilon}$} & $C_{\mu}$ \\
\hline 1.00 & 1.30 & 1.44 & 1.92 & 0.09 \\
\hline
\end{tabular}

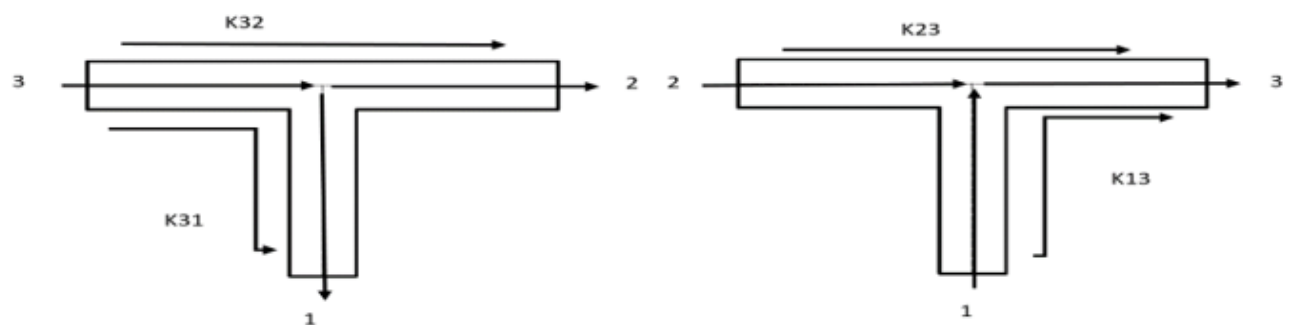

(a)

(b)

Fig 6. Configurations of flow arrows indicate the direction of flow.

The arrangement of flow through a tee-junction with a straight main pipe is shown in Fig 6. The common branch is 3 (inlet flow) in non-symmetrical dividing, 1 and 2 are outlet branches. Also, the common branch is 3 (outlet flow), 1 and 2 are inlet branches for non-symmetrical combining flow type. The energy equation for the division flow is given by:

$\mathrm{P}_{3}+0.5 \rho \mathrm{U}_{3}^{2}=\mathrm{Pi}+0.5 \mathrm{U}_{\mathrm{i}}^{2}+\mathrm{f}_{\mathrm{i}} \frac{\mathrm{l}_{\mathrm{i}}}{\mathrm{D}_{\mathrm{i}}} 0.5 \rho \mathrm{U}_{\mathrm{i}}^{2}+\mathrm{f}_{3} \frac{\mathrm{l}_{3}}{\mathrm{D}_{3}} 0.5 \rho \mathrm{U}_{3}^{2}+\Delta \mathrm{p}_{3 \mathrm{i}}$

Also, the energy equation for the combined flow is given by:

$P i+0.5 \rho U_{i}^{2}=P_{3}+0.5 U_{3}^{2}+f_{i} \frac{l_{i}}{D_{i}} 0.5 \rho U_{i}^{2}+f_{3} \frac{l_{3}}{D_{3}} 0.5 \rho U_{3}^{2}+\Delta p_{i 3}$

In which $\Delta P_{3 i}$ is the energy loss (pressure drop) due to the dividing of flow. 
Where $\Delta \mathrm{P}_{3 \mathrm{i}}=\left(\mathrm{P}_{3}+0.5 \rho \mathrm{U}_{3}^{2}\right)-\left(\mathrm{P}_{\mathrm{i}}+0.5 \rho \mathrm{U}_{\mathrm{i}}^{2}\right)$

in which $\Delta P_{i 3}$ is the energy loss (pressure drop) due to the combination of flow.

Where $\Delta \mathrm{P}_{\mathrm{i} 3}=\left(\mathrm{P}_{\mathrm{i}}+0.5 \rho \mathrm{U}_{\mathrm{i}}^{2}\right)-\left(\mathrm{P}_{3}+0.5 \rho \mathrm{U}_{3}^{2}\right)$

The loss coefficient of dividing flow is defined by:

$\left(\mathrm{K}_{\mathrm{d}}\right)_{31}=\frac{\Delta \mathrm{P}_{31}}{0.5 \rho \mathrm{U}_{3}^{2}}$

The flow rate ratio for

$\left(\mathrm{K}_{\mathrm{d}}\right)_{31}=\frac{\mathrm{Q}_{1}}{\mathrm{Q}_{3}}$

$\left(\mathrm{K}_{\mathrm{d}}\right)_{32}=\frac{\Delta \mathrm{P}_{32}}{0.5 \rho \mathrm{U}_{3}^{2}}$

The flow rate ratio for

$\left(\mathrm{K}_{\mathrm{d}}\right)_{32}=\frac{\mathrm{Q}_{2}}{\mathrm{Q}_{3}}$

Similarly, the loss coefficient of combining flow is defined by:

$\left(\mathrm{K}_{\mathrm{c}}\right)_{13}=\frac{\Delta \mathrm{P}_{13}}{0.5 \rho \mathrm{U}_{3}^{2}}$

The flow rate ratio for

$\left(\mathrm{K}_{\mathrm{c}}\right)_{13}=\frac{\mathrm{Q}_{1}}{\mathrm{Q}_{3}}$

$\left(\mathrm{K}_{\mathrm{c}}\right)_{23}=\frac{\Delta \mathrm{P}_{23}}{0.5 \rho \mathrm{U}_{3}^{2}}$

The flow rate ratio for

$$
\left(\mathrm{K}_{\mathrm{d}}\right)_{23}=\frac{\mathrm{Q}_{2}}{\mathrm{Q}_{3}}
$$




\section{CFD Simulation and Result}

The losses coefficient is calculated from equations (13), (15), (17), and (19). the pressure drop is calculated from equations (11) and (12). Also, The velocity profile with ansys fluent for combination and division flow type.

\subsection{For Non-Symmetrical Dividing}

\subsubsection{Loss Coefficients Effect of Flow Rate Ratio and Re}

Figs. 7 and 8 show the variation of the loss coefficient $K_{31}, K_{32}$ at different inlet Re numbers and flow rate ratios. It is important to note the inlet Reynolds number measured at low to high for turbulent flow. In contrast, compares the loss coefficient with literature at high Re 30000. The loss coefficient is already independent of the Re number. Figs .7a and 8a, show the loss coefficient for dividing flow with flow rate ratio at different Re numbers and comparing with previous work. The $\mathrm{K}_{31}$ decreases with an increased flow rate ratio for the present work, $\mathrm{G}$. Can [4] and Costa[8] the same behaviour but the Miller[1] and Crawford [6] are different because of the variations in geometry, the material used, working fluid, and difference in the inlet boundary condition. It shows when the flow rate ratio decreased at 0.8 at non fully develop flow and recirculation occurs near the $\mathrm{T}$-junction. The higher value of flow rate causing a pressure drop. The $\mathrm{K}_{32}$ decreased with an increased flow rate ratio for the present work and Crawford [6] opposite that the Miller [1] and G.Can [4]. The difference between the numerical result (present work) and others is because of the different variations in geometry and inlet flow conditions. Figs. $7 b$ and $8 b$, have shown the variation of loss coefficients with a flow rate ratio at $\operatorname{Re} 30000$. The coefficient minimum value of flow rate of $\mathrm{K} 31$ nearly $0.6, \mathrm{k}_{32}$ nearly 0.6 equal 0.998 to 0.274 , respectively. Figs. 7c and 8c, depict the loss coefficients with different Re numbers at a flow rate ratio of 0.1 . The loss coefficient is decreasing, when increasing in Re because of the increase in the velocity inlet. the circulation of the $\mathrm{T}$ - junction and disturbing the coming flow, therefore, the pressure drop is taking place. 


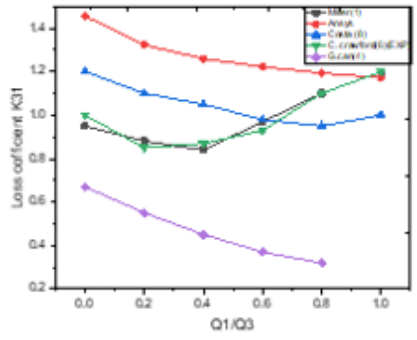

(a)

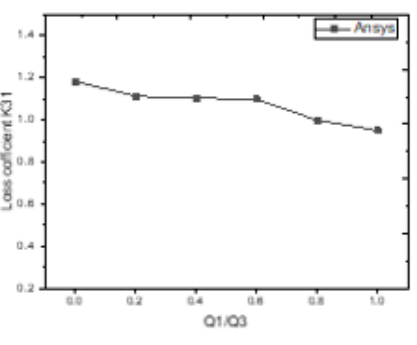

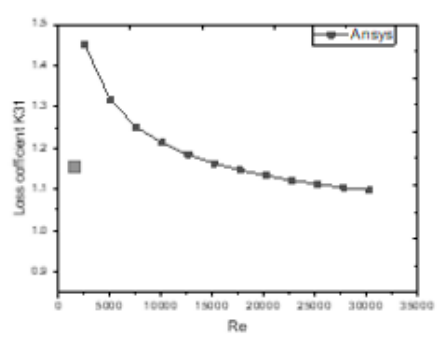

(c)

Fig 7. Variation of loss coefficient $\mathrm{K}_{31}$ comparison with literature(a) effect flow rate ratio at different $\mathrm{Re}$ (b) effect flow rate ratio at Re 30000 (c) effect of different Re at flow rate 0.1.

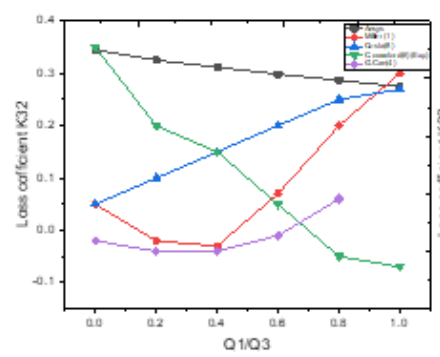

(a)

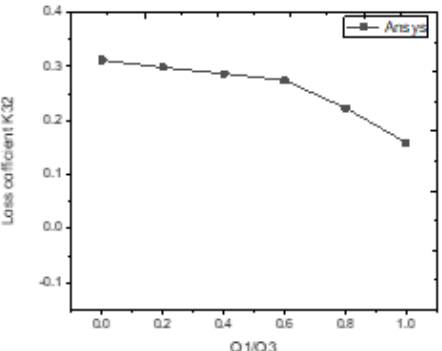

(b)

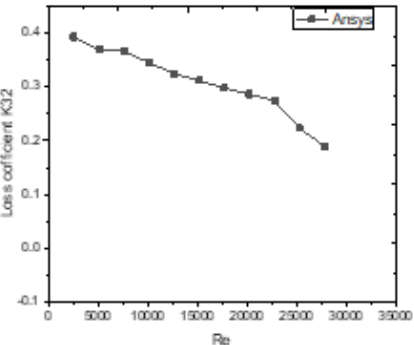

(c)

Fig 8. variation of loss coefficient $\mathrm{K}_{32}$ and comparison with literature (a) effect flow rate ratio at different $\operatorname{Re}(b)$ effect flow rate ratio at $\operatorname{Re} 30000$ (c) effect of different $\operatorname{Re}$ at a flow rate ratio 0.1.

\subsubsection{Head Losses (Energy Losses)}

The minor losses in-branch dividing noticed the pressure drop increased with increased velocity inlet in Figs.9(a), (b) show the pressure drop with inlet velocity due to friction in the pipe and turbulence losses at the junction. The head loss in branches 3-1 reached nearly $(800 \mathrm{~Pa})$ at a velocity of $1.2 \mathrm{~m} / \mathrm{s}$. Also, the pressure loss in branches $2-3$ reached nearly (200 Pa) at the same velocity. The reason for the difference is dependent on the flow rate ratio where $\mathrm{Q}_{1} / \mathrm{Q}_{3}$ is equal to 0.1 , and the pressure drop is normalized by the square of the velocity. 


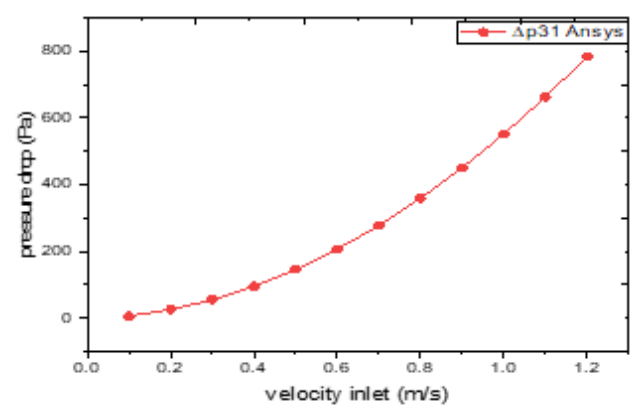

(a)

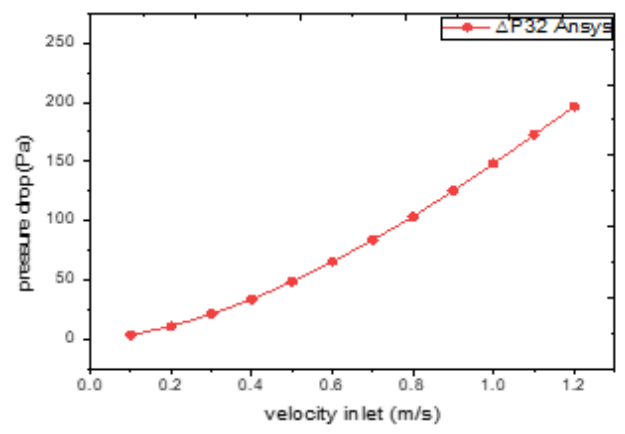

(b)

Fig 9. Head losses(a) the branch 3-1 (b) the branch 3-2.

\subsubsection{Velocity Profile}

Figs 10 and 11 show the velocity profile and streamline where the velocity inlet is $1.2 \mathrm{~m} / \mathrm{s}$ and Reynolds number is (30000) for variation of flow rate ratio 0.1, 0.5, and 0.8. In Figs 10a, b, and c noticed that the velocity profile for the value of velocity in branch $3-2(1.07 \mathrm{~m} / \mathrm{s})$ and branch $3-1(0.142 \mathrm{~m} / \mathrm{s})$ at a flow rate ratio 0.1 . Whereas the velocity in branch $3-2(0.6 \mathrm{~m} / \mathrm{s})$ and branch $3-1(0.7 \mathrm{~m} / \mathrm{s})$ at flow rate ratio 0.5 . Finally, inflow rate ratio 0.8 the velocity in the branch $3-2$ $(0.321 \mathrm{~m} / \mathrm{s})$ and branch $3-1(0.948 \mathrm{~m} / \mathrm{s})$. It is clear the formation of vortex and recirculation in the lateral branch near the junction at a flow rate ratio of 0.5 and increased 0.8 , especially in branches 3-1. Small eddies arise in branches 3-1 when increase the flow rate ratio at 0.8 increased the size of eddies.

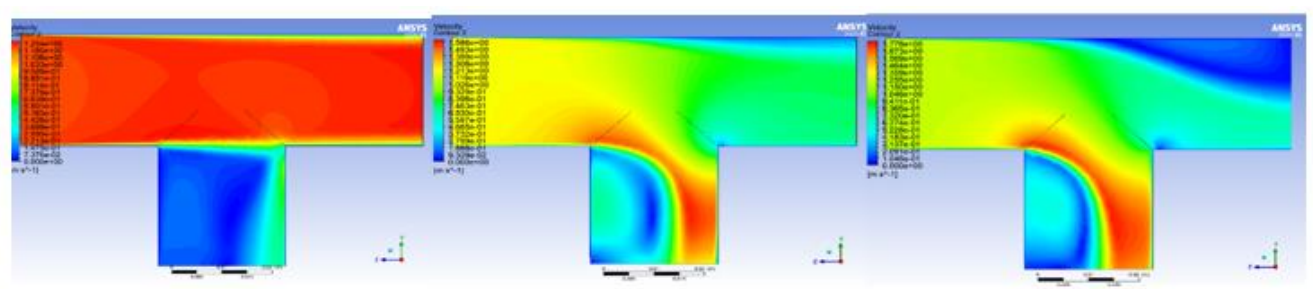

(a)

(b)

(c)

Fig 10. Velocity profile at different flow rate ratio (a) 0.1 (b) 0.5 (c) 0.8 .

In contrast, in Fig 11(a), (b), and (c) shows the streamline of the same velocity is $(1.2 \mathrm{~m} / \mathrm{s})$ with different flow rate ratio $(0.1,0.5$, and 0.8$)$. The streamline helped to visualize all different possible flow patterns in tee junction. The non-symmetrical dividing shows very little fluid tends to branch 3-1 and maximum fluid moving in the straight pipe branch 3-2 at flow rate 0.1. Also, 
the change of flow rate ratio to 0.5 noticed the same mount fluid in the two-leg of the tee causing circulation of the branch 3-1. Lastly, when changing the flow rate ratio to 0.8 the fluid is forced to move to branches 3-1 which causing the small eddies in two branches.

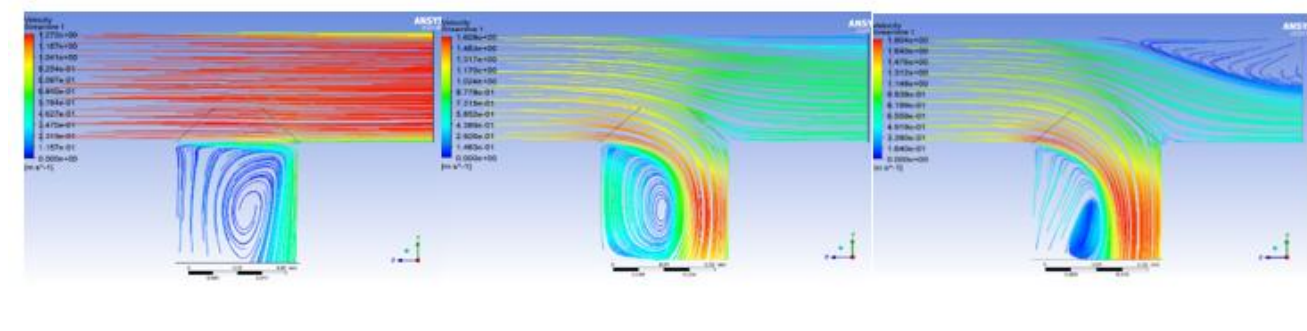

(a)

(b)

(c)

Fig 11. Streamline at different flow rate ratio (a) 0.1 (b) 0.5 and (c) 0.8 .

Fig $12 \mathrm{a}, \mathrm{b}$, and c shows the velocity profile at the different cross-sections of the tee junction pipe at inlet velocity $(1.2 \mathrm{~m} / \mathrm{s}), \operatorname{Re}(30000)$, and flow rate ratio 0.5 . Fig 12a shows the velocities at various distances of the main pipe. The stable value of velocities at $\mathrm{z}=0.039,0.03$ and $0.02 \mathrm{~m}$ and the same behaviour to hence non reached to fully developed flow. The maximum value of the velocity at $\mathrm{z}=0.01 \mathrm{~m}$ and centreline midpoint of tee because the separation of fluid affected of developing flow. The profile velocities at the cross-section depict non-fully developed flow because the length of the downstream is not sufficient to reach the fully developed flow. Fig $12 \mathrm{~b}$ shows the velocity at the different lines in branch $3-1$ of the outlet at line $y=-0.01 \mathrm{~m}$ the velocities increased due to the separation of fluid flow in two branches. The velocities at other lines behave the same in maximum value at $\mathrm{z}=-0.005 \mathrm{~m}$ but decrease at $\mathrm{z}=0.0 \mathrm{~m}$ due to the circulation in the branch. Fig12c shows the velocity at the different lines in branches 3-2 observed the same behaviour at the line $\mathrm{z}=-0.01,-0.02,-0.03 .-0,039$. The higher value of the velocity at $\mathrm{y}=0.005 \mathrm{~m}$ and returned to a low value due to the small eddies.

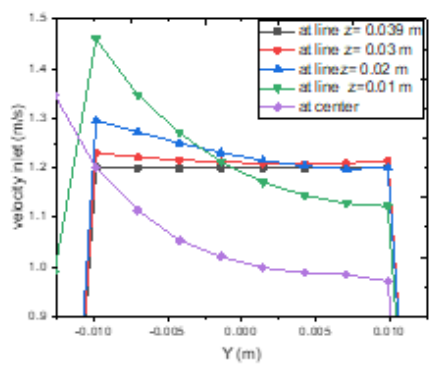

(a)

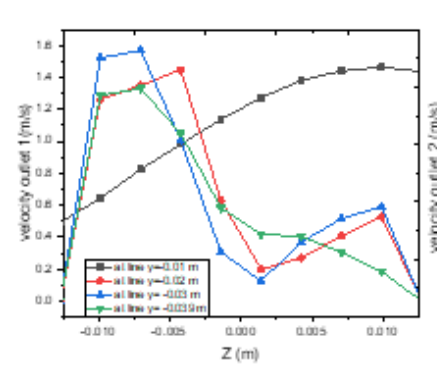

(b)

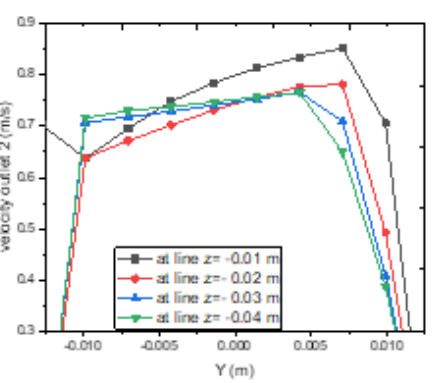

(c)

Fig 12. comparison of the velocity profile at $\mathrm{V} 3=1.2 \mathrm{~m} / \mathrm{s}$ (a) the inlet branch (b) the outlet branch $3-1$ (c) the outlet 2 branches $3-2$. 


\subsection{For Non-Symmetrical Combining}

\subsubsection{Loss Coefficient Effect of Flow Rate Ratio and Re}

Figs. 13 and 14 provided the variation of the loss coefficient $\mathrm{K}_{13}, \mathrm{~K}_{23}$ at different inlet $\mathrm{Re}$ numbers and flow rate ratios. In important, when compares the loss coefficient with literature at high Re 30000. Figs.13a and 14a, showing the loss coefficient with flow rate ratio at different Re numbers and comparison with the previous work. The loss coefficient $\mathrm{K}_{13}, \mathrm{~K}_{23}$ decreased with an increased flow rate ratio but in Miller increased. The difference between the loss coefficient when comparing the present work with literature for many reasons is the variations in geometry, the material used, working fluid, and difference inlet boundary conditions. Figs. $13 \mathrm{~b}$ and $14 \mathrm{~b}$, have shown the variation of loss coefficients with flow rate ratio at $\operatorname{Re} 30000$ decreased when flow rate ratio increased. The $\mathrm{K}_{13}, \mathrm{~K}_{23}$ at a flow rate ratio of 0.8 decreases reached at 0.333 and 0.47 respectively. Figs. 13c and 14c, depict the loss coefficient for different Re numbers at a flow rate ratio of 0.5 . The $\mathrm{K}_{13}, \mathrm{~K}_{23}$ decrease with an increased flow rate ratio. The generation of eddies and swirl on the outlet causes therefore rotational kinetic energy and increased pressure drop.

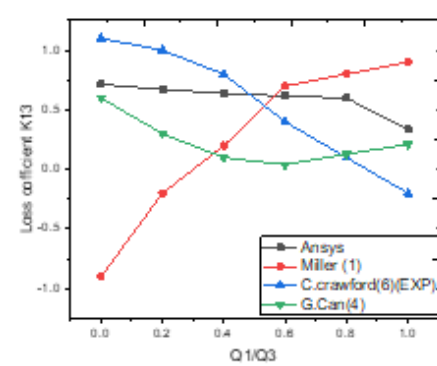

(a)

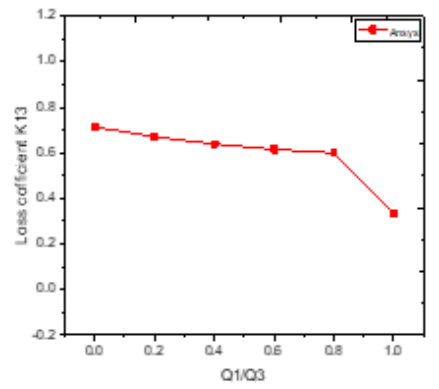

(b)

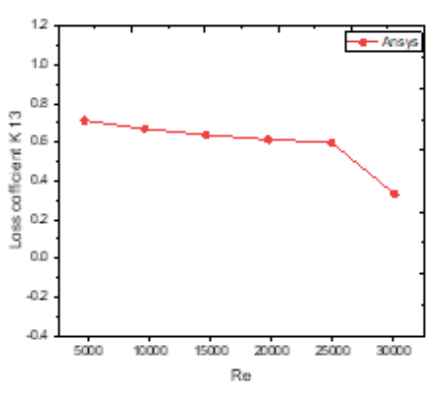

(c)

Fig 13. Variation of loss coefficient $\mathrm{K}_{13}$ and comparison with literature (a) effect flow rate ratio at different $\operatorname{Re}(b)$ effect flow rate ratio at $\operatorname{Re} 30000$ (c) effect of different Re at a flow rate ratio 0.5. 


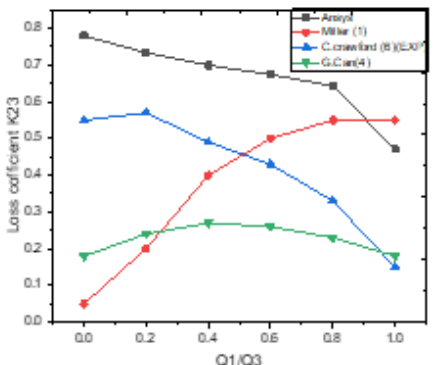

(a)

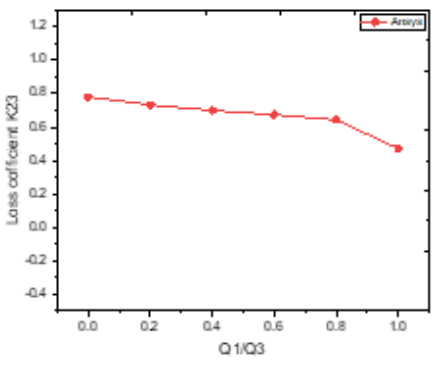

(b)

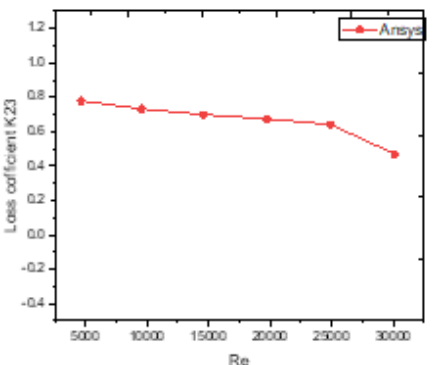

(c)

Fig 14. variation of loss coefficient $K_{23}$ and comparison with literature (a) effect flow rate ratio at different Re, (b) effect flow rate ratio at $\operatorname{Re} 30000$ (c) effect of different Re at a flow rate ratio 0.5.

\subsubsection{Head Loss (Energy Losses)}

Figs.15 shows the pressure drop (the minor losses) for non-symmetrical combing with inlet velocity observed the pressure drop increases with increased velocity inlet. Also, the pressure drops in branches 1-3 reached nearly (526 Pa) ANSYS at a velocity inlet of $0.6 \mathrm{~m} / \mathrm{s}$ for two branches. However, the pressure drops in branches 2-3 reached nearly (576 Pa) in ANSYS at the same velocity for two inlets. The reason for the difference is dependent on the flow rate ratio where Q1/Q3 equals 0.5. the higher value of pressure drops at increased velocity towards the outlet.

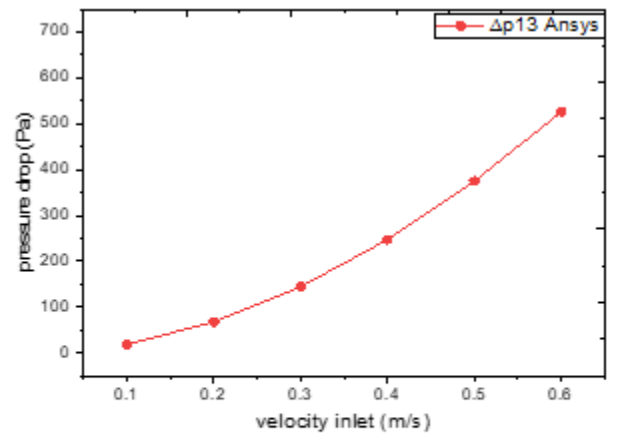

(a)

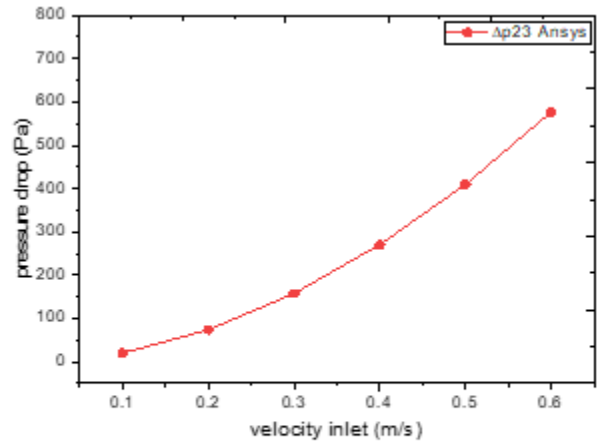

(b)

Fig 15. Head losses(a) the branch 1-3 (b) the branch 2-3.

\subsubsection{Velocity Profile}


Figs $16 a, b$, and $c$ show the velocity profile at $\operatorname{Re}(30000)$ for variation of flow rate ratio $0.1,0.5,0.8$. Noticed that the value of velocity inlet in branch $2-3(0.9 \mathrm{~m} / \mathrm{s})$ and branch $1-3$ $(0.3 \mathrm{~m} / \mathrm{s})$ in flow rate ratio 0.1 . Whereas the velocity inlet in branch $2-3(0.6 \mathrm{~m} / \mathrm{s})$ and branch $1-$ $3(0.6 \mathrm{~m} / \mathrm{s})$ at flow rate 0.5 . Finally, the flow rate ratio 0.8 the velocity in the branch $2-3(0.2$ $\mathrm{m} / \mathrm{s})$ and branch $3-1(1 \mathrm{~m} / \mathrm{s})$. It is cleared that the generation of vortex and circulation at a flow rate of 0.5 and increased 0.8 , especially in the outlet branch. no separation of flow is observed at a flow rate ratio of 0.1 . When the flow rate ratio is high, the flow separation is present in the junction, but the degree of separation is little at a flow rate of 0.8 .

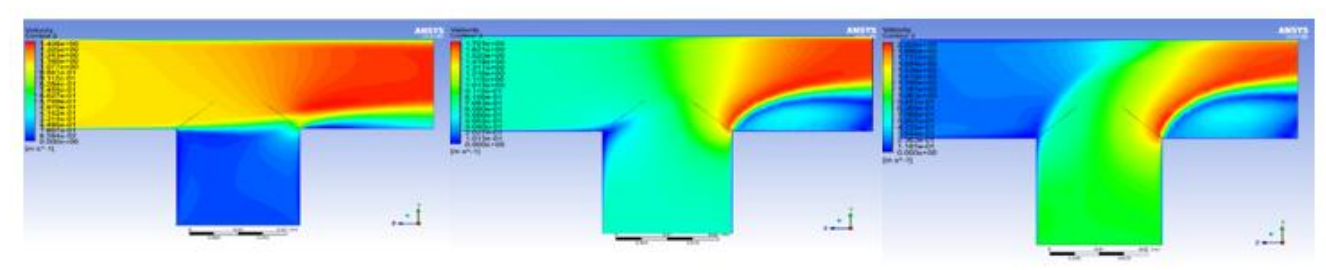

(a)

(b)

(c)

Fig 16. Velocity profile with different flow rate ratio (a) 0.1 (b) 0.5 (c) 0.8 .

On the other hand, in Figs 17a, b, and c manifest the streamline of the same Re (30000) and the outlet velocity $(1.2 \mathrm{~m} / \mathrm{s})$ with different flow rates $(0.1,0.5$, and 0.8$)$. The non-symmetrical combing shows the high-velocity zone observed in the outlet branch of the T-junction. Fig $17 \mathrm{~b}$ illustrates the streamlines change the direction and create a recirculation near the tee junction zone. the velocity is the same for the two branches there is less circulation which there is less pressure loss towards the outlet. Fig $17 \mathrm{c}$ at flow rates ratio 0.8 the velocity inlet 2 is great than the velocity inlet 1 the result in decreasing the pressure towards the outlet.

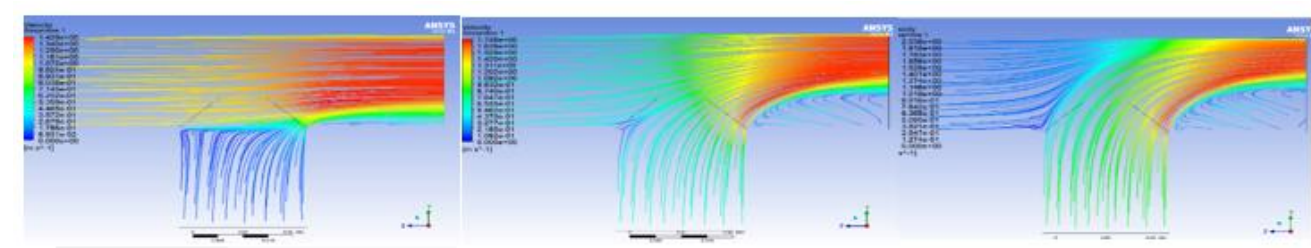

(a)

(b)

(c)

Fig 17. Streamline with different flow rate ratio (a) 0.1 (b) 0.5 (c) 0.8 .

Figs 18 illustrate the velocity profile at different line cross-sections of Tee at $\operatorname{Re}(30000)$ and velocity value equal 0.6 for two inlets flow rate ratio 0.5 . Fig 18 a shows the velocities stable at line $\mathrm{z}=0.039,0.03$, and $0.02 \mathrm{~m}$ non reached to fully develop flow but increased at line $\mathrm{z}=0.01$ and centerline because of reached to T-junction. The velocity at the centreline is higher when merged with velocity from inlet 2 . Fig $18 \mathrm{~b}$ shows the velocities at the different lines at inlet 2 . the velocities stable at line $\mathrm{y}=-0.039,-0.03$, and $-0.02 \mathrm{~m}$ the same with inlet 1 . Fig $18 \mathrm{c}$ represents the velocities of the outlet at the different lines it clears the raised velocity at line $\mathrm{z}=$ $-0.02,-0.03$, and $-0.039 \mathrm{~m}$ due to merge the two inlets. Line $\mathrm{z}=-0.01$ The profile velocities at 
the cross-section depict non-fully developed flow because the length of the downstream is not sufficient to reach the fully developed flow.

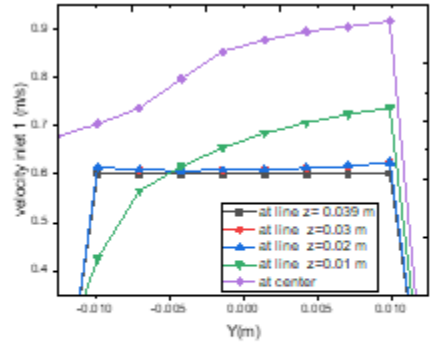

(a)

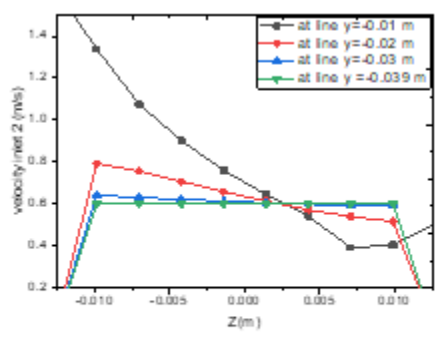

(b)

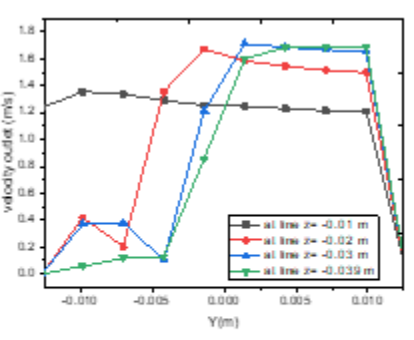

(c)

Fig 18. Comparison of the velocity profile at $\mathrm{V}_{3}=1.2 \mathrm{~m} / \mathrm{s}$ (a) the inlet 1 branch (b) the inlet 2 branch (c) the outlet branch.

\section{Conclusion}

The predicted the pressure loss coefficient, and pressure drop, velocity profile in $\mathrm{T}$-junction with the turbulent flow with a sharp edge. Studied two cases the non-symmetrical dividing and non-symmetrical combing for different flow rate ratios and Reynold number with area ratio equal one. The comparison of numerical results with literature work. The pressure drops increases with an increase in the velocity inlet for two cases of flow. The loss coefficient was dependent on the flow rate ratio. In the non-symmetrical combing, the velocity in the outlet branch is high with formation recirculation. The non-symmetrical dividing the small eddies and recirculation with increased flow rate to 0.8 in branch 1-3. Due to recirculation of flow from a branch pipe, the value of the pressure loss coefficient $\mathrm{K}_{23}$ for branch pipe was higher than $\mathrm{K}_{13}$ for straight pipe.

\section{Nomenclature}

\begin{tabular}{|lr|lr|}
\hline $\begin{array}{l}\mathrm{L} 1, \mathrm{~L} 2, \mathrm{~L} 3(\mathrm{~m}) \\
1,2 \text { and } 3\end{array}$ & length of pipe & $\begin{array}{l}\mathrm{A}\left(\mathrm{m}^{2}\right) \\
\text { section area }\end{array}$ & cross- \\
\hline $\begin{array}{l}\mathrm{D} 1(\mathrm{~m}) \\
\text { main pipe }\end{array}$ & diameter of the & $\begin{array}{l}\mathrm{D} 2(\mathrm{~m}) \\
\text { branch pipe }\end{array}$ & diameter of \\
\hline $\begin{array}{l}\mathrm{C}_{1} \varepsilon, \mathrm{C}_{2} \varepsilon, \mathrm{C}_{\mathrm{k}}(-) \\
\text { constants }\end{array}$ & stander K- epsilon model & $\begin{array}{l}\mathrm{K}\left(\mathrm{m}^{2} / \mathrm{s}^{2}\right) \\
\text { kinetic energy }\end{array}$ & turbulent \\
\hline $\begin{array}{l}\mathrm{Q}\left(\mathrm{m}^{3} / \mathrm{s}\right) \\
\text { rate }\end{array}$ & flow & $\mathrm{t}(\mathrm{s})$ & production \\
\hline $\begin{array}{l}\mathrm{Re}(-) \\
\text { number }\end{array}$ & Reynolds & $\begin{array}{l}\mathrm{P}_{\mathrm{k}}(-) \\
\text { of } \mathrm{K}\end{array}$ & pressure \\
\hline $\begin{array}{l}\mathrm{S}(-) \\
\text { strain tensor redulus of the mean rate of the }\end{array}$ & $\mathrm{P}(\mathrm{Pa})$ & & \\
\hline
\end{tabular}




\begin{tabular}{|c|c|}
\hline $\begin{array}{l}\mathrm{K}_{\mathrm{d}}(-) \\
(3-2),(3-1)\end{array}$ & $\begin{array}{l}\mathrm{K}_{\mathrm{c}}(-) \quad \text { pressure loss coefficient for combing } \\
(2-3),(1-3)\end{array}$ \\
\hline $\begin{array}{l}\mathrm{P}_{\mathrm{b}}(-) \\
\text { buoyancy }\end{array}$ & mean velocity ith \\
\hline velocity (mean x- & velocity (mean y- \\
\hline $\begin{array}{l}\mathrm{U}(\mathrm{m} / \mathrm{s}) \\
\text { velocity }\end{array}$ & velocity (fluct.ith \\
\hline $\begin{array}{l}\Delta \mathrm{p}(\mathrm{Pa}) \\
\text { pressure }\end{array}$ & $\begin{array}{l}\rho \\
\text { density }\end{array}$ \\
\hline $\begin{array}{l}\mu(\mathrm{kg} / \mathrm{ms}) \\
\text { viscosity }\end{array}$ & $\begin{array}{l}\mu_{\mathrm{t}}(\mathrm{kg} / \mathrm{ms}) \\
\text { viscosity }\end{array}$ \\
\hline $\begin{array}{l}\alpha(-) \\
\text { shape factor }\end{array}$ & $\begin{array}{l}\varepsilon\left(\mathrm{m}^{2} / \mathrm{s}^{2}\right) \\
\text { dissipation rate }\end{array}$ \\
\hline $\begin{array}{l}\sigma_{\mathrm{k}}(-) \\
\text { prandtl of } \mathrm{K}\end{array}$ & $\begin{array}{l}\sigma \varepsilon(-) \\
\text { prandtl of } \varepsilon\end{array}$ \\
\hline
\end{tabular}

\section{References}

[1] D. Miller, Internal Flow Systems by Donald Stuart Miller (z-lib.org)1984.pdf.

[2] A. Marc Serre, A. Jacob Odgaard, z Member, ASCE, and Rex A. Eider, 3 Fellow, "ENERGY LOSS AT COMBINING PIPE JUNCTION," vol. 120, no. 7, pp. 808-830, 1994.

[3] F. Z. Sierra-Espinosa, C. J. Bates, and T. O’Doherty, “Turbulent flow in a $90^{\circ}$ pipe junction. Part 2: Reverse flow at the branch exit," Comput. Fluids, vol. 29, no. 2, pp. 215-233, 1998, doi: 10.1016/S0045-7930(99)00005-5.

[4] G. Gan and S. B. Riffat, "Numerical determination of energy losses at duct junctions," Appl. Energy, vol. 67, no. 3, pp. 331-340, 2000, doi: 10.1016/S0306-2619(00)00026-X.

[5] K. Oka, "Energy Losses at Tees With Large.pdf," J. Fluids Eng., 2005.

[6] N. Crawford, "Pressure Losses at Bends and Junctions .pdf," 2005.

[7] J. Pérez-García, E. Sanmiguel-Rojas, J. Hernández-Grau, and A. Viedma, "Numerical and experimental investigations on internal compressible flow at T-type junctions," Exp. Therm. Fluid Sci., vol. 31, no. 1, pp. 61-74, 2006, doi: 110.1016/j.expthermflusci.2006.02.001.

[8] N. P. Costa, R. Maia, M. F. Proença, and F. T. Pinho, "Edge effects on the flow characteristics in a 90 deg tee junction," Journal of Fluids Engineering, Transactions of the ASME, vol. 128, no. 6. pp. 1204-1217, 2006, doi: 10.1115/1.2354524.

[9] P. R. Vasava, "Fluid Flow in T-Junction of Pipes," 2007.

[10] Mohammed .A. Abdulwahida, Prof. Niranjan .K. Injetib,Ass. Prof. Sadoun. F. Dakhil, "Numerical prediction of pressure loss of fluid in a T-junction," Int. J. Energy Environ., vol. 4, no. 2, pp. 253-264, 2013.

[11] Mohammed .A.Abdulwahida, Prof. Niranjan .K. Injetib, Ass. Prof. Sadoun Fahad Dakhil, "CFD Simulations and Flow Analysis Through a T-Junction Pipe,” Int. J. Eng. Sci. Technol., vol. 4, no. 7, pp. 3392-3407, 2012.

[12] G. Paál and F. T. Pinho, "Numerical predictions of turbulent flow in a $90^{\circ}$ tee junction," no. May 2014, 2003.

[13] C. S. M. Gajbhiye1, A.K. Chaturvedi2, S.S. Sawant1, S.N. Gosavi1, H.A. Kulkarni1, "CFD SIMULATIONS OF FLOW AND PRESSURE DROP IN T-JUNCTION.pdf," 2015.

[14] Y. B. Lukiyanto, I. N. G. Wardana, W. Wijayanti, and M. A. Chiron, "Flow visualization pattern on sharp edge T-junction through dividing flow channel," Appl. Mech. Mater., vol. 493, pp. 6267, 2014, DOI: 10.4028/www.scientific.net/AMM.493.62.

[15] J. Stigler, R. Klas, M. Kotek, and V. Kopecký, "The fluid flow in the t-junction. The comparison 
of the numerical modeling and PIV measurement," Procedia Eng., vol. 39, no. December, pp. 19-27, 2012, doi: 10.1016/j.proeng.2012.07.003.

[16] M. D. Bassett, D. E. Winterborne, and R. J. Pearson, "Calculation of steady flow pressure loss coefficients," vol. 215, pp. 861-881, 2016.

[17] N. A. Ferede, "Numerical analysis and CFD simulation of fluid flow in T- Junction pipe By using ANSYS CFX," vol. 10, no. 10, pp. 504-513, 2019. 